\title{
Pengaruh Spesies Inang dan Sumber Nutrisi Terhadap Produksi Spora Fungi Mikoriza Arbuskula
}

\author{
Delvian \\ Departemen Kehutanan Fakultas Pertanian Universitas Sumatera Utara \\ JI. Tri Dharma Ujung No. 2 Kampus USU Padang Bulan Medan \\ Telp. 061-8220605, Faks. 061-8201920, e-mail: Delvian@usu.ac.id \\ Diterima 04-05-2007 Disetujui 18-03-2008
}

\begin{abstract}
An experiment to study the effect of host species and source of nutrient on spore production of an Arbuscule Mycorrhizal Fungus, Gigaspora margarita, has been carried out. Combination treatments studied consisted of host species (Zea mays and Pueraria javanica) and nutrient factor (no fertilizer, fertilizer and Red Hyponex). Growth medium used was a mix of soil and sand in 1: 1 ratio (v/v) which was sterilized. Results of the experiment showed that spore production of G. margarita was affected by host species and also by nutrient applied, though there was no interaction between the two factors. However, P. javanica produced more spore than $Z$. mays. Treatment with Red Hyponex result much higher spores than others, but however without fertilizer produced more spores than Urea, TSP and $\mathrm{KCl}$ fertilizers.
\end{abstract}

Keywords: Gigaspora margarita, host species, fertilizer, spore

\section{PENDAHULUAN}

Fungi mikoriza arbuskula (FMA) merupakan sekelompok mikroorganisme tanah yang berperan penting dalam penyerapan fosfat $(P)$ dari tanah. Sebagian besar tanaman secara alami dikolonisasi oleh FMA. Akan tetapi dibutuhkan inokulum FMA untuk mendapatkan keuntungan yang lebih besar dari simbiosis ini. Beberapa metoda telah dikembangkan dalam produksi inokulum FMA, seperti teknik nutrient film (Mosse et al, 1980) dan kultur pot (Wood 1985). Namun demikian teknik kultur pot lebih berkembang karena sederhana dan mudah dilaksanakan (Chulan 1991). Produksi inokulum FMA dengan metoda ini dikembangkan pertama kali oleh Mosse dan Gerdemann tahun 1954 (Wood 1985).

Dalam produksi inokulum FMA dengan teknik kultur pot, tanaman inang sangat diperlukan karena FMA adalah simbion obligat. Beberapa penelitian terdahulu menunjukkan bahwa species tanaman mempunyai kemampuan yang berbeda dalam menghasilkan spora FMA. (Bagyaraj \& Manjunanth 1980) menyatakan bahwa Glomus fasciculatum berkembang baik jika inangnya adalah rumput Guinea, Sementara itu Glomus claroideum, Glomus etunicatum, Glomus mosseae dan Glomus macrocarpum berkembang sangat baik pada rumput bahia daripada jagung dan rumput sudan (Strubble \& Skipper 1988) dalam (Thomson et al, 1997).

Pada sisi lain tanaman membutuhkan unsur hara untuk pertumbuhan dan perkembangannya. Pada awalnya perbanyakan FMA dengan tanaman jagung sebagai inang menggunakan larutan Johnson sebagai sumber hara. Akan tetapi penyediaan larutan ini tidak praktis dan mahal. Oleh karena itu untuk menghasilkan inokulum dengan biaya yang murah perlu dicari alternatif sumber nutrisi yang lain. Salah satu sumber nutrisi yang dapat digunakan adalah Hyponex Merah (N:P:K : 255-20). Dalam penelitian ini telah dipelajari masalah produksi spora FMA dalam kaitannya dengan pengaruh spesies tanaman inang dan sumber nutrisi.

\section{BAHAN DAN METODE}

Penelitian ini dilaksanakan di rumah kaca Fakultas Pertanian USU sejak Juni - Oktober 2006. Media tumbuh yang digunakan adalah campuran tanah dan pasir (1:1, $\mathrm{v} / \mathrm{v})$. Sifat kimia dari tanah yang digunakan adalah $\mathrm{pH}$ $\left(\mathrm{H}_{2} \mathrm{O}\right) 4,8, \mathrm{~N}$ total $0.047 \%, \mathrm{P}_{2} \mathrm{O}_{5}$ total $0,032 \%, \mathrm{P}_{2} \mathrm{O}_{5}$ tersedia $12 \mathrm{mg} / \mathrm{kg}, \mathrm{K}_{2} \mathrm{O} 0,009 \%$, CEC 13,47 me/100 g tanah. Percobaan ini dilaksanakan dengan menggunakan Rancangan Acak Lengkap (RAL) Faktorial. Perlakuan yang disusun terdiri atas faktor spesies tanaman inang (Zea mays dan Pueraria 


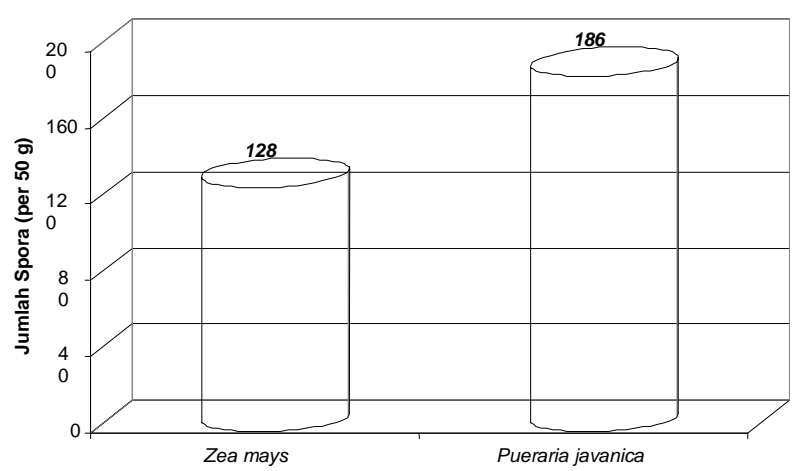

Gambar 1. Jumlah spora G. margarita pada inang yang berbeda

javanica) dan faktor sumber hara (tanpa pemupukan, pemupukan dengan Urea-TSP-KCl, dan pemupukan dengan Hyponex Merah). Setiap perlakuan diulang sebanyak 5 kali.

Media tumbuh disterilisasi pada suhu $90^{\circ} \mathrm{C}$ selama 1 jam yang dilakukan secara series sebanyak 3 kali. Selanjutnya dimasukkan ke dalam pot sebanyak $1 \mathrm{~kg}$ per pot. Benih yang telah berkecambah selanjutnya ditanam dalam pot sesuai dengan perlakuan. Inokulum FMA (Gigaspora margarita) sebanyak 50 spora diletakkan di bawah akar tanaman inang. Untuk perlakuan pupuk NPK didasarkan pada rekomendasi pupuk untuk perbanyakan FMA di Laboratorium Biologi Tanah FP USU dimana setiap pot tanaman Z. Mays dan $P$ javanica diberikan $2 \mathrm{~g}$ urea, $2 \mathrm{~g}$ TSP dan $2,5 \mathrm{~g}$ $\mathrm{KCl}$. Sedangkan untuk perlakuan Hyponex Merah (255-20) setiap pot disiram dengan konsentrasi $2 \mathrm{~g} / \mathrm{l}$ air sebanyak $20 \mathrm{ml} /$ pot setiap minggu. Selama percobaan tanaman disiram dengan aquades. Setelah tanaman berumur 12 minggu dilakukan pengeringan dengan cara tanpa dilakukan penyiraman selama 2 minggu. Selanjutnya tanaman dipotong dan media tumbuh dan akar tanaman inang dicampur menjadi satu. Selanjutnya diambil $50 \mathrm{~g}$ inokulum (campuran media tumbuh dan akar tanaman inang) untuk menghitung kepadatan jumlah spora yang dihasilkan. Teknik yang digunakan dalam mengekstraksi spora CMA adalah teknik tuang-saring (Pacioni 1992), dan dilanjutkan dengan teknik sentrifugasi (Brundrett et al, 1996).

\section{HASIL DAN PEMBAHASAN}

Hasil pengamatan jumlah spora G. margarita menunjukkan bahwa spesies tanaman inang dan sumber nutrisi mempengaruhi produksi spora, akan tetapi secara statistik tidak terdapat interaksi antara kedua faktor tersebut. Pada perlakuan jenis tanaman

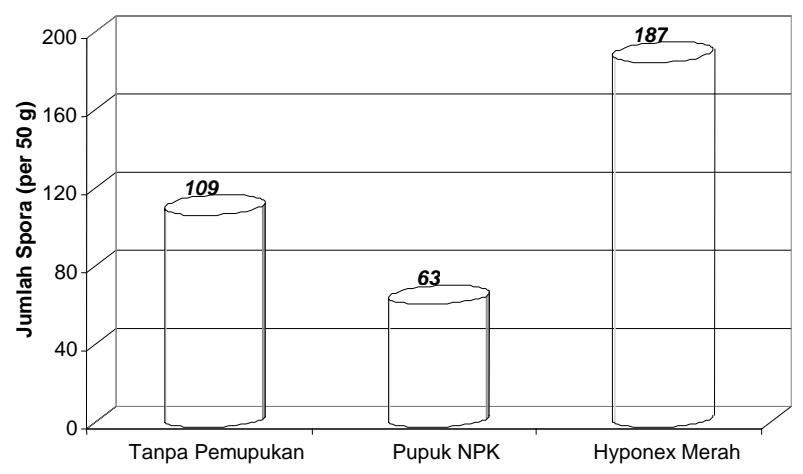

Gambar 2. Jumlah spora G. margarita pada berbagai sumber nutrisi

inang, G. margarita dapat tumbuh baik. Kedua spesies tanaman tersebut biasa digunakan sebagai inang dalam perbanyakan FMA, akan tetapi untuk produksi spora $G$. margarita penggunaan $P$. javanica menghasilkan spora lebih banyak daripada $Z$. mays (Gambar 1). Menurut Menge (1984), persyaratan tanaman yang cocok untuk produksi spora FMA adalah mampu beradaptasi dengan kondisi pertumbuhan, merupakan tanaman inang bagi Fungi, cepat tumbuh, sistem perkembangan akar yang intensif, dan tidak mengandung patogen.

Spora G margarita tumbuh baik pada semua jenis sumber nutrisi meskipun terdapat perbedaan dalam kepadatan spora antar perlakuan sumber nutrisi (Gambar 2). Hasil percobaan menunjukkan bahwa pada pot tanpa pemupukan menghasilkan spora cukup tinggi. Sebaliknya, penambahan pupuk (Urea-TSP-KCl) menurunkan jumlah spora $G$. margarita yang dihasilkan.

Media yang digunakan untuk memproduksi spora FMA harus mempunyai kandungan nutrisi yang rendah (Cooper 1984; Menge 1984). Analisa tanah menunjukkan bahwa tanah yang digunakan dalam percobaan ini mempunyai kandungan nutrisi sangat rendah-sedang. Oleh karena itu tampaknya kondisi ini cocok untuk memproduksi spora G. margarita. (Habte \& Aziz 1991) menyatakan bahwa di antara nutrisi tanaman, jumlah $\mathrm{P}$ khususnya dalam bentuk tersedia sangat mempengaruhi simbiosis FMA. Kandungan $P$ yang tinggi akan menghambat perkembangan FMA dan mengurangi derajad kolonisasi (Abbot \& Robson 1984; Menge 1984).

Nitrogen yang tinggi dalam bentuk ammonium akan menghambat perkembangan FMA dibandingkan dengan nitrat. Demikian juga jika kalium terdapat dalam jumlah banyak akan menurunkan derajad kolonisasi yang ada (Smith \& Read 1997). Secara umum, perkembangan 
FMA yang tinggi membutuhkan keseimbangan nutrisi untuk memenuhi kebutuhan tanaman (Menge 1984). Dalam percobaan ini diduga nutrisi yang terdapat dalam tanah sudah mencukupi untuk pertumbuhan dan perkembangan G. margarita, sedangkan penambahan pupuk Urea, TSP dan $\mathrm{KCl}$ menghambat perkembangan dan kolonisasi sehingga jumlah spora G margarita yang dihasilkan berkurang.

Sumber nutrisi yang berasal dari Hyponex Merah menghasilkan jumlah spora FMA yang sangat tinggi dibandingkan pemberian pupuk Urea, TSP dan $\mathrm{KCl}$. Dalam penggunaannya larutan Hyponex Merah diberikan beberapa kali dengan konsentrasi rendah. Adanya perbedaan sumber dan frekuensi pemberian nutrisi antara larutan Hyponex Merah dan pupuk Urea, TSP dan $\mathrm{KCl}$, diduga penyebab adanya perbedaan pengaruh terhadap kolonisasi dan perkembangan $G$. margarita.

Respon FMA terhadap pemupukan $\mathrm{N}$ dan $\mathrm{P}$ tergantung pada isolat FMA. Pemberian pupuk dengan kandungan $\mathrm{N}$ yang cukup tinggi dapat meningkatkan produksi spora beberapa jenis FMA (Clark 1997) Sedangkan (Douds \& Schenck 1990) mendapatkan produksi spora Glomus intraradices yang rendah dengan pemberian $\mathrm{N}$ yang tinggi. Dalam percobaan ini produksi spora G. margarita cukup banyak (187 spora/ $50 \mathrm{~g}$ tanah) dengan pemberian larutan Hyponex Merah dimana kandungan $\mathrm{N}$ sebesar $25 \%$.

Kolonisasi FMA seringkali terhambat dengan pemberian $\mathrm{P}$ dalam bentuk tersedia dalam jumlah yang banyak (Powell \& Bagyaraj 1984; Baon 1994). Lebih lanjut, jumlah $\mathrm{N}$ dan $\mathrm{P}$ secara langsung akan mempengaruhi kolonisasi akar oleh FMA yang pada akhirnya akan mempengaruhi produksi spora FMA. Dalam percobaan ini kepadatan spora yang tinggi diperoleh dari perlakuan larutan Hyponex Merah dengan kandungan $\mathrm{N}$ yang tinggi tetapi $\mathrm{P}$ rendah. Dengan demikian pendekatan untuk meningkatkan jumlah spora FMA dalam tanah dapat dilakukan dengan menyediakan inang yang cocok dan sumber nutrisi dengan kandungan $\mathrm{P}$ rendah tetapi $\mathrm{N}$ tinggi seperti halnya Hyponex Merah.

\section{KESIMPULAN}

Spesies inang dan sumber nutrisi sangat mempengaruhi produksi spora G. margarita. Produksi spora tertinggi diperoleh dengan inang $P$. javanica dan Hyponex Merah sebagai sumber nutrisi.

\section{UCAPAN TERIMA KASIH}

Pada kesempatan ini penulis ingin menyampaikan terima kasih kepada Pimpinan dan Staf Laboratorium Bioteknologi Kehutanan, Pusat Penelitian Bioteknologi IPB atas bantuan inokulumnya. Selanjutnya ucapan terima kasih juga disampaikan kepada rekan-rekan di Laboraotium Biologi Tanah dan Rumah Kaca Fakultas Pertanian Universitas Sumatera Utara atas segala bantuan dan kerjasama yang baik.

\section{DAFTAR PUSTAKA}

Abbott, LK \& Robson, AD. 1982. The Role of VA mycorrhizae fungsi in agriculture and the selection of fungi for inoculation. Aust. J. Agric. Res. 33: 389-395.

Bagyaraj, DJ \& Manjunanth, A. 1980. Selection of a suitable host for mass production of VA mycorrhizal inoculum. Plant and Soil 55: 459-498.

Baon, JB. 1994. Growth of mycorrhizal coca on red-yellow podzolic soil. Pelita Perkebunan 9: 148-154

Brundrett MC, Bougher N, Dells B, Grove T, \& Malajczuk N. 1996. Working with mycorrhizas in forestry and agriculture. ACIAR. Canberra. 374 hal.

Chulan, AH. 1991. Mycorrhiza in A Technical Handbook. UNESCO Regional Training Course on Utilization of Benefecial Microorganisms for Enhancement of Crop Productivity. University Pertanian Malaysia, Selangor. Darul Ehsan, Malaysia, 19-30 August, 1991.

Clark RB. 1997. Arbuscular mycorrhizal adaptation, spore germination, root colonization, and host plant growth and mineral acquisition at low pH. Plant and Soil 192: 15-22.

Cooper, KM. 1984. Physiology of VA mycorrhizal associations. Di Dalam: Powell CL dan Bagyaraj DJ (eds.) VA Mycorrhiza. CRC Press. Florida, USA.

Douds, DD \& Schenck, NC. 1990. Increase sporulation of vesicular arbuscular mycorrhizal fungi by manipulation of nutrient regime. Appl. Environ. Microbial. 56: 413-418.

Habte, M \& Aziz, T. 1991. Relative important of $\mathrm{Ca}, \mathrm{N}$ and $\mathrm{P}$ in enhancing mycorrhizal activity in Leucaena leucocephala grown in an oxisol subjected to stimulated erosion. $J$. Plant. Nut. 14: 429-442

Menge, JA. 1984. Inoculum production in VA mycorrhizal. Di Dalam: Powell CL dan Bagyaraj DJ (eds.) VA Mycorrhiza. CRC Press. Florida, USA.

Mosse, B, Thompson, JP \& Smith SE. 1980. Development of VA mycorrhizal in plants fed with nutrient solution in sand and nutrient film culture. Report rothamsted Exp. Sta. For 1978. Part 1

Pacioni G. 1992. Wet sieving and decanting techniques for the extraction of spores of VA mycorrhizal fungi. Hal: 317-322. Di Dalam: Norris, J.R., D.J. Read and A.K. Varma (Eds.) Methods in Microbiology. Vol. 24. Academic Press Inc. San Diego.

Powell, CL \& Bagyaraj, DJ. 1984. VA mycorrhiza. CRC Press, Inc. Boca, Raton, Florida.

Smith SE \& Read DJ. 1997. Mycorrhizal symbiosis. Second edition. Academic Press. Harcourt Brace \& Company Publisher. London. Hal: 32-79.

Thomson BD, Robson AD \& Abbott LK. 1990. Mycorrhizas formed by Gigaspora calospora and Glomus fasciculatum on subterranean clover in relation to soluble carbohydrate concentrations in roots. New Phytol. 114: 217-225.

Wood, T. 1985. Commercial pot culture inoculum production. Quality control and other headaches. Di Dalam: Molina, R (ed). Proc. 6th North Amer. Conf. Mycorrhizae. Forest Res. Lab. Publ., Oregon, USA. 